\title{
L-carnitine supplementation of sows during pregnancy improves the suckling behaviour of their offspring
}

\author{
Carmen Birkenfeld, Holger Kluge and Klaus Eder* \\ Institute of Nutritional Sciences, Martin-Luther-Universität Halle-Wittenberg, Emil-Abderhalden-Strasse 26, D-06108 Halle/Saale, \\ Germany
}

(Received 25 January 2006 - Revised 6 April 2006 - Accepted 13 April 2006)

\begin{abstract}
It has been shown that L-carnitine supplementation of sows increases their milk production and the postnatal growth of the suckling piglets. To test the hypothesis that this effect is due to an improved suckling behaviour of the piglets, two experiments with sows were performed. Two groups of thirteen or ten sows each (in experiments 1 and 2, respectively) were fed diets with or without supplemental L-carnitine during pregnancy (125 mg/ d) and lactation $(250 \mathrm{mg} / \mathrm{d})$. After birth, the litters of all sows were standardised to equal sizes of eleven and nine piglets per litter in experiments 1 and 2, respectively. In experiment 1, the piglets of L-carnitine-supplemented sows had a higher total suckling time per day on days 3, 6 and 9, and greater weight gains during the suckling period, than the piglets of control sows $(P<0 \cdot 05)$. In experiment 2 , all litters were taken away from their mothers and switched to other sows. Half of the control sows and half of the L-carnitine-supplemented sows were given litters born to control sows, the other half of each group being given litters born to L-carnitine-supplemented sows. Piglets born to L-carnitine-supplemented sows had a higher total suckling time per day on day 3 and greater body weight gains during the first $14 \mathrm{~d}$ compared with piglets born to control sows $(P<0 \cdot 05)$. This study shows that piglets born to sows supplemented with L-carnitine are able to suckle for longer, which enables them to obtain more milk and grow faster than piglets born to control sows.
\end{abstract}

L-Carnitine: Sow: Piglet: Suckling behaviour

Several studies have shown that supplementing sows with L-carnitine during pregnancy and lactation increases their reproductive performance. Sows supplemented with L-carnitine had fewer stillborn piglets, more piglets born alive and greater litter weights (Musser et al. 1999b; Eder et al. 2001; Ramanau et al. 2002, 2004, 2005). Moreover, it has been shown that litters of sows supplemented with L-carnitine gain more weight during the suckling period than do litters of control sows (Musser et al. 1999b; Eder et al. 2001; Ramanau et al. 2002, 2004, 2005).

The postnatal growth of piglets depends on their intake of energy and nutrients with the milk (Pluske \& Dong, 1998). The contents of energy and nutrients, as well as the fatty acid composition of the milk, do not differ between control sows and sows supplemented with L-carnitine (Ramanau et al. 2004, 2005). Using the weigh-suckle-weigh method, however, we have shown that the piglets of sows supplemented with L-carnitine are able to suckle more milk from the sow than are the piglets of control sows, which may explain their higher growth rate during the suckling period (Ramanau et al. 2004, 2005).

The reason for the higher milk intake of piglets from sows supplemented with L-carnitine is unclear. The milk production of sows is strongly influenced by litter size, piglet weights and suckling intervals (King et al. 1997; Spinka et al. 1997; Auldist et al. 1998, 2000). If piglets suckle more frequently, with shorter intervals between sucklings, they will obtain more milk, thus causing the sow's milk production to rise. The hypothesis of the present study was that piglets of sows supplemented with L-carnitine would be able to suckle more frequently or for longer periods owing to an increased L-carnitine status, obtaining more milk from the sow and therefore growing faster than the piglets of control sows.

To test this hypothesis, we performed two experiments with sows. In the first experiment, sows were assigned to a control group and a group supplemented with L-carnitine during pregnancy and lactation. After delivery, litters were standardised to an identical size in order to avoid the potential effects of differences in litter size on milk production, and were suckled from their mothers during a $28 \mathrm{~d}$ lactation period. The second experiment was performed to clarify whether alterations in the suckling behaviour of the piglets were due to prenatal or postnatal effects of L-carnitine. In that experiment, sows were assigned to a control group and a group treated with L-carnitine. After delivery, all the litters were taken away from their mothers and switched to other sows. Half of the control sows and half of the L-carnitine-supplemented sows were given litters born to control sows, the other half of each group being given litters born to L-carnitine-supplemented sows.

If an improvement in suckling behaviour were due to prenatal effects, litters born to sows supplemented with L-carnitine should have had a higher suckling activity and have grown 
faster during the suckling period than litters born to control sows, irrespective of whether they were suckled by control sows or by sows supplemented with L-carnitine. If the improved suckling behaviour of the piglets was due to postnatal effects of L-carnitine, litters suckled by sows supplemented with L-carnitine should have had a higher suckling activity and have gained more weight during the suckling period than litters suckled by control sows, irrespective of whether they were born to control sows or to sows supplemented with L-carnitine.

\section{Materials and methods}

\section{Animals and housing}

All animal procedures described followed established guidelines for the care and handling of laboratory animals and were approved by the regional council of Saxony-Anhalt.

The first experiment was performed with twenty-six crossbred sows (German Landrace $\times$ Large White) in their second parity with a body weight of 179 (SE 3) kg. They were assigned to two groups, a control group and a group treated with L-carnitine, of thirteen sows each. Twenty-four hours after the weaning of their first litter, the sows received 800 IU pregnant mare serum gonadotrophin (Intergonan 6000; Intervet, Unterschleißheim, Germany) by intramuscular injection to stimulate oestrus. Seventy-two hours later they were injected with 500 IU human chorionic gonadotrophin (Ovogest 5000, Intervet). A further $26 \mathrm{~h}$ after that, they were artificially inseminated with sperm from Pietrain boars, a second insemination following $14 \mathrm{~h}$ later.

The second experiment was performed with 40 gilts (German Landrace $\times$ Large White) with a body weight of 143 (SE 1) $\mathrm{kg}$. They were assigned to two groups, a control group and a group treated with L-carnitine, of twenty sows each. Their sexual cycle was blocked for $15 \mathrm{~d}$ by the administration of Altrenogest (Regumate; Hoechst Roussel Vet. N.V., Frankfurt, Germany). Twenty-four hours after the last dose of Regumate, they were injected with 800 IU pregnant mare serum gonadotrophin, followed $80 \mathrm{~h}$ later by an injection of 500 IU human chorionic gonadotrophin (Ovogest 5000; Intervet). A further $24 \mathrm{~h}$ after the human chorionic gonadotrophin injection, they were artificially inseminated with sperm from Pietrain boars, followed by a second injection $14 \mathrm{~h}$ later.

In the first experiment, nine of the thirteen sows in the control group and all thirteen sows in the L-carnitine treated group conceived. In the second experiment, thirteen of the twenty sows in the control group and sixteen of the of the twenty sows in the L-carnitine treated group conceived. Farrowing was induced on day 115 of pregnancy by intramuscular injection of prostaglandin $\mathrm{F}_{2 \alpha}$ (Cloprostenol; Medistar $\mathrm{GmbH}$, Holzwickede, Germany). Within $2 \mathrm{~d}$ after farrowing, the litter sizes of the sows to be considered during lactation were standardised to avoid potential effects of differences in litter size on milk production and weight gains of the litters during the suckling period. In the first experiment, litters of eight randomly selected sows from each group were standardized to eleven piglets per litter.

In the second experiment, litters of ten sows from each group were standardised to nine piglets per litter within $2 \mathrm{~d}$ of farrowing. Sows with more than nine or eleven piglets, respectively, had the surplus piglets taken away, and sows with fewer than nine or eleven piglets were given piglets from other sows of the same group. Piglets removed from sows and piglets given to sows were selected on the basis of their body weight. The average weight of piglets of each sow after litter standardisation was matched to that before standardisation. Surplus piglets were nursed by the remaining sows of each group that were not taking part in the study.

In the second experiment, all the litters were taken away from their mothers and switched to other sows. Litters of half of the control sows or L-carnitine-treated sows, respectively, were switched to sows of the other experimental group, and litters of the other half of each group were switched to different sows of the same treatment. This resulted in four combinations in the second experiment: piglets born to control sows and suckled by different control sows; piglets born to control sows and suckled by sows supplemented with L-carnitine; piglets born to sows supplemented with L-carnitine and suckled by control sows; piglets born to sows supplemented with L-carnitine and suckled by different sows supplemented with L-carnitine.

The sows were kept in single crates until day 30 of pregnancy. From day 30 to day 110 of pregnancy, the sows were kept in groups of six to eight in pens measuring $45 \mathrm{~m}^{2}$, which had fully slatted floors, nipple drinkers and electronic feeding stations. On day 110 of pregnancy, they were moved to the farrowing accommodation, where they were housed in single farrowing pens. Prior to farrowing, rubber mats were put down as a lying surface for the piglets. An IR heater was suspended above each rubber mat to keep the temperature for the newborn piglets at a constant $35^{\circ} \mathrm{C}$. Piglets were suckled for $28 \mathrm{~d}$. The climate in the dry sow accommodation and the farrowing unit was maintained at a temperature of $19 \pm 2^{\circ} \mathrm{C}$ and at $60-80 \%$ relative humidity by means of an air-conditioning system. A light-dark cycle ( $12 \mathrm{~h}$ light- $12 \mathrm{~h}$ dark) was applied.

\section{Diets and feeding}

In both experiments, two commercial sow diets were used, whose composition and nutrient concentrations are shown in Table 1. The first diet ('gestation diet' SF-SATT; Deuka, Könnern, Germany) was fed during pregnancy. Two different batches of this diet were used in experiments 1 and 2, which varied slightly in their composition and nutrient concentrations. Until day 30 of pregnancy, each sow was fed $3.5 \mathrm{~kg}$ gestation diet individually. From day 30 to day 110 of pregnancy, when the sows were kept in groups, they had free access to the diets. The sows' daily feed intake was recorded by means of an electronic sow-feeding station (type IVOG 2FR VH; HokoFarm, Insentec B.V., Marknesse, The Netherlands). From day 110 of pregnancy to farrowing, each sow was fed $2.5 \mathrm{~kg} / \mathrm{d}$ of this diet.

The second diet ('lactation diet'; Lactosan; Deuka) was fed during the lactation period. The same batches of this diet were used in experiments 1 and 2. On the day of farrowing, the sows were fed $1.5 \mathrm{~kg}$ of the diet, the amount then being successively increased $(2 \mathrm{~kg} / \mathrm{d}$ on days 1 and 2 of lactation; $4 \mathrm{~kg} / \mathrm{d}$ on days $3-7$ of lactation; $5.5 \mathrm{~kg} / \mathrm{d}$ from days 8 to 14 ; $6.0 \mathrm{~kg} / \mathrm{d}$ from days 15 to 25$)$. Thereafter the sows received 
Table 1. Composition of the diets used during pregnancy and lactation

\begin{tabular}{|c|c|c|c|}
\hline & \multicolumn{2}{|c|}{ Gestation diet } & \multirow{2}{*}{$\begin{array}{c}\text { Lactation diet } \\
\text { Experiments } 1 \text { and } 2\end{array}$} \\
\hline & Experiment 1 & Experiment 2 & \\
\hline \multicolumn{4}{|l|}{ Ingredient (g/kg) } \\
\hline Dried sugar beet pulp & 260 & 260 & - \\
\hline Barley & 150 & 150 & 150 \\
\hline Wheat & - & - & 344 \\
\hline Wheat bran & 380 & 382 & 170 \\
\hline Extracted soyabean meal & - & - & 160 \\
\hline Extracted sunflower meal & 110 & 140 & - \\
\hline Maize & - & - & 80 \\
\hline Wheat gluten & 33 & - & - \\
\hline Triticale & 25 & 30 & - \\
\hline Soyabeans & - & - & 30 \\
\hline Vegetable oil & 2 & 2 & 27 \\
\hline Molasses & 25 & 20 & - \\
\hline Mineral premix & 10 & 11 & 24 \\
\hline Premix containing vitamins and amino acids & 5 & 5 & 15 \\
\hline \multicolumn{4}{|l|}{ Nutrients } \\
\hline Crude protein $(\mathrm{g} / \mathrm{kg})$ & 138 & 147 & 182 \\
\hline Crude fibre $(\mathrm{g} / \mathrm{kg})$ & 120 & 135 & 48 \\
\hline Crude ash ( $(\mathrm{g} / \mathrm{kg})$ & 59 & 61 & 46 \\
\hline Crude fat $(\mathrm{g} / \mathrm{kg})$ & 30 & 30 & 59 \\
\hline L-Carnitine (mg/kg) & $7 \cdot 4$ & $6 \cdot 5$ & 2.5 \\
\hline Metabolisable energy $(\mathrm{MJ} / \mathrm{kg})^{*}$ & $9 \cdot 0$ & 8.7 & $12 \cdot 6$ \\
\hline
\end{tabular}

${ }^{*}$ Calculated according to recommendations by Gesellschaft für Ernährungsphysiologie (1987).

$5.0 \mathrm{~kg} / \mathrm{d}$ until weaning on day 28 . Water was provided from nipple drinker systems throughout the whole feeding period.

\section{Supplementation of L-carnitine}

Sows in the treatment group were supplemented with $125 \mathrm{mg}$ L-carnitine/d during pregnancy and $250 \mathrm{mg}$ L-carnitine/d during lactation. L-carnitine was given as tablets containing L-carnitine $(62.5 \mathrm{mg} /$ tablet $)$, lactose and dextrose; Lohmann Animal Health, Cuxhaven, Germany). The tablets were administered once daily in the morning (09.00 hours) by hand. During pregnancy, each sow of the treatment group was given two tablets; during lactation, each sow was given four tablets. Amounts of L-carnitine administered to the sows during pregnancy and lactation were selected according to our recent studies (Ramanau et al. 2002, 2004). Control animals were given the same tablets without L-carnitine.

\section{Data recording}

Body weights (using scales with an accuracy of $100 \mathrm{~g}$ ) of the sows were recorded on days 1 and 105 of pregnancy and on the day of weaning. Individual piglets were weighed at birth (not later than $6 \mathrm{~h}$ after birth) and at 7, 14, 21 and $28 \mathrm{~d}$ of age using scales with an accuracy of $10 \mathrm{~g}$. All the sows that conceived were evaluated for number of piglets born, piglet weights and litter weights at birth.

\section{Determination of nutrients in the diets}

Concentrations of crude nutrients in the diets were analysed according to the official German VDLUFA methodology (Bassler \& Buchholz, 1993). The metabolisable energy of the diet was calculated as recommended by the German nutrition society (Gesellschaft für Ernährungsphysiologie, 1987).

\section{Analysis of L-carnitine in plasma, milk and diet}

Piglets were bled by puncture of the venous plexus in the jugular fossa on day 1 (6h postpartum) and at 14 and $28 \mathrm{~d}$ of age. Plasma was obtained by centrifuging the blood $\left(1100 \mathrm{~g}, 10 \mathrm{~min}, 4^{\circ} \mathrm{C}\right)$ and stored at $-20^{\circ} \mathrm{C}$ pending analysis. On the day of birth and on day 11 of lactation, the sows were given $15 \mathrm{IU}$ oxytocin (Atarost GmbH\&Co, Twistringen, Germany) by intramuscular injection, and $80-100 \mathrm{ml}$ milk was expressed manually from all the active teats of each sow. Milk was stored at $-20^{\circ} \mathrm{C}$ pending analysis.

The concentrations of total carnitine in plasma, milk and diet were determined by a radiochemical method, which is based on the conversion of carnitine to $\left[{ }^{3} \mathrm{H}\right]$ acetylcarnitine by carnitine-O-acetyltransferase (McGarry \& Foster, 1976).

\section{Determination of piglet suckling behaviour}

In the first experiment, eight randomly selected sows from each group and their litters were filmed with a video camera (time-lapse cassette recorder: Panasonic AG-6124-E, Matsushita Electric Ind. Co. Ltd, Osaka, Japan; camera: Visicom B/W-Kamera CCD-BW2012, MHM Electronic GmbH, Lindhorst, Germany) over a $24 \mathrm{~h}$ period on days 3, 6 and 9 of lactation. In the second experiment, all the sows and their litters were filmed on day 3 of lactation. The video tapes were viewed with a video recorder (video recorder: Panasonic AG 7350-E; monitor: Panasonic WV-CM 1430, Matsushita).

The number of sucklings was counted, and the mean duration of one suckling act and total suckling time were measured with a stopwatch. A suckling act was deemed to 
have occurred if the number of piglets nursing the udder was at least $60 \%$ of the sow's litter size (six piglets/litter in experiment 1; five piglets/litter in experiment 2). The total suckling time/d was calculated as the sum of the individual nursing episodes. As lactation progresses, piglets' suckling behaviour changes: piglets more often tend to nose the udder individually and fall asleep there, making an accurate distinction between suckling and sleeping piglets extremely difficult or speculative. For this reason, it was no longer possible to measure the suckling time after day 9 of lactation.

\section{Statistical analysis}

All statistics were carried out using SAS software (SAS institute Inc., Cary, NC, USA). All dependent variables in the first experiment, and the dependent variables of pregnancy and litter performance in the second experiment, were analysed with a mixed linear model (procedure mixed, version 8.2; SAS Institute Inc.) that included the treatment of sows (control sow $v$. sow supplemented with L-carnitine) as a fixed effect. In the second experiment, data on lactation were evaluated by using a mixed linear model (procedure mixed, version 8.2; SAS Institute Inc.) with treatment of sow (control sow $v$. sow supplemented with L-carnitine), origin of the piglet (piglet of control sow $v$. piglet of sow supplemented with L-carnitine) and their interaction as classification factors. Results are expressed as least-square means and standard errors of the means. Means were considered significantly different for $P<0.05$.

\section{Results}

Experiment 1: Feed intake and body weights of the sows during pregnancy and lactation, number and birth weights of piglets

Body weights on days 1 and 10, and average daily feed intake during the entire pregnancy, did not differ between the two groups of sows. Taking all pregnant sows in the experiment, values for control sows $(n$ 9) and sows supplemented with L-carnitine ( $n$ 13) were: body weight day 1, 177 v. 179 (SEM 3) $\mathrm{kg}$; body weight day 108, 248 v. 242 (SEM 5) kg; daily feed intake, $3.4 v$. 3.4 (SEM $0 \cdot 1) \mathrm{kg}$. Taking only the eight sows from each group who were studied during lactation, there was again no difference in these parameters; for control sows $(n 8) v$. sows supplemented with L-carnitine $(n 8)$ values were: body weight day $1,176 v .181$ (SEM 5) kg; body weight day 108, 246 v. 247 (SEM 6) kg; daily feed intake, 3.3 v. 3.4 (SEM 0.1) kg. Body weight at weaning and feed intake during lactation also did not differ between the two groups of sows; for control sows ( $n$ 8) v. sows supplemented with L-carnitine $(n$ 8): body weight at weaning, 208 v. 213 (SEM 7) $\mathrm{kg}$; daily feed intake, 6.5 v. 6.4 (SEM 0.04$) \mathrm{kg}$.

Total litter size, number of piglets born alive and birth weights of the piglets and litters did not differ between control sows and sows supplemented with L-carnitine. Values for control sows ( $n$ 9) and sows supplemented with L-carnitine ( $n$ 13) were as follows: number of piglets born/litter, $11.2 v .12 .4$ (SEM 1.0); number of piglets born alive/litter, 11.1 v. 12.3 (SEM 1.0); litter weight, 14.9 v.16.7 (SEM 1.2) kg; piglet weight, $1.37 v .1 .38$ (SEM 0.07 ) $\mathrm{kg}$. The variation in body weights of the piglets in a litter was, however, lower in L-carnitine-supplemented sows than in control sows (the SD of piglet weights in the litters of control sows and the litters of L-carnitine-supplemented sows being 0.32 and $0.17 \mathrm{~kg}$, respectively).

The sows which were considered during lactation also showed no differences in these parameters. Values for control sows $(n 8)$ and sows supplemented with L-carnitine $(n 8)$ were: number of piglets born/litter, $11.9 v .12 .8$ (SEM 1.0); number of piglets born alive/litter, 11.8 v. 12.6 (SEM 1.0); litter weight, 15.6 v. 17.5 (SEM 1.2) kg; piglet weight, 1.34 v. 1.42 (SEM $0 \cdot 09) \mathrm{kg}$.

\section{Experiment 1: Suckling behaviour and weight gains of the} piglets during the suckling period

The suckling behaviour of the piglets was studied at 3,6 and $9 \mathrm{~d}$ of age. On all $3 \mathrm{~d}$, the number of sucklings/d was no different between piglets from the control sows and from the sows supplemented with L-carnitine (Table 2). On days 3 and 6, the average duration of one suckling was, however, significantly higher in the piglets of sows supplemented with L-carnitine than in the piglets of control sows $(P<0 \cdot 05$; Table 2$)$. On day 9 , the average duration of one suckling was marginally higher in the piglets of sows supplemented with L-carnitine than in the piglets of control sows $(P<0 \cdot 10$; Table 2$)$. The total suckling time/d was higher in the piglets from sows supplemented with L-carnitine than in those from control sows on all $3 \mathrm{~d}(P<0 \cdot 05$; Table 2).

Average body weights of the piglets after the standardisation of litter sizes to eleven piglets/litter did not differ between the piglets of control sows and of sows supplemented with L-carnitine (Table 2). On days 7 and 28, body weights were greater in piglets from sows supplemented with L-carnitine than in piglets from control sows $(P<0 \cdot 05$; Table 2$)$. On days 14 and 21, the piglets of sows supplemented with L-carnitine were also slightly heavier than those of control sows, but the differences were not significant $(P>0 \cdot 05$; Table 2$)$. The body weight gain between day 1 and day 28 was more in the piglets of sows supplemented with L-carnitine than in the piglets of control sows $(P<0 \cdot 05)$.

\section{Experiment 2: Feed intake and body weights of the sows} during pregnancy and lactation, number and birth weights of piglets

The body weights on days 1 and 105, and the average daily feed intake during the entire pregnancy, did not differ between the two groups of sows. Taking all pregnant sows in the experiment, values for control sows ( $n$ 13) and sows supplemented with L-carnitine ( $n$ 16) were: body weight day 1 , 144 v. 142 (SEM 2) kg; body weight day 105, 206 v. 204 (SEM 3) $\mathrm{kg}$; daily feed intake, $3 \cdot 0$ v. $3 \cdot 1$ (SEM 0.1) kg.

Taking the ten sows of each group that were studied during lactation, there was again no difference in these parameters; for control sows $(n$ 10) $v$. sows supplemented with L-carnitine (n 10): weight day 1, 143 v. 141 (SEM 2) kg; body weight day 105, 207 v. 205 (SEM 4) kg; daily feed intake during pregnancy, $3 \cdot 1$ v. $3 \cdot 1$ (SEM $0 \cdot 1) \mathrm{kg}$. The average daily feed intake during lactation and weights at weaning did not differ between control sows suckling piglets born to control sows 
Table 2. Suckling behaviour (number of sucklings/d, average duration of one suckling and total suckling time/d) at days 3 , 6 and 9 of age, and body weights and weight gains of piglets of control sows and piglets of sows supplemented with L-carnitine (experiment 1 )

(Values are least-square means)

\begin{tabular}{|c|c|c|c|c|}
\hline & Piglets of control sows & Piglets of sows supplemented with L-carnitine & SEM & $P$ \\
\hline \multicolumn{5}{|l|}{ Suckling behaviour ( $n$ 8) } \\
\hline \multicolumn{5}{|l|}{ Day 3} \\
\hline Number of sucklings/d & 43.5 & 44.9 & $1 \cdot 79$ & 0.60 \\
\hline Average duration of one suckling (min) & $4 \cdot 73^{\mathrm{a}}$ & $5 \cdot 82^{\mathrm{b}}$ & 0.30 & 0.02 \\
\hline Total suckling time/d $(\mathrm{h})$ & $3.45^{\mathrm{a}}$ & $4 \cdot 36^{b}$ & 0.28 & 0.04 \\
\hline \multicolumn{5}{|l|}{ Day 6} \\
\hline Number of sucklings/d & $38 \cdot 0$ & 37.5 & $1 \cdot 33$ & 0.79 \\
\hline Average duration of one suckling (min) & $3 \cdot 27^{\mathrm{a}}$ & $4 \cdot 62^{\mathrm{b}}$ & 0.40 & 0.03 \\
\hline Total suckling time/d $(\mathrm{h})$ & $2 \cdot 07^{\mathrm{a}}$ & $2 \cdot 85^{\mathrm{b}}$ & 0.22 & 0.03 \\
\hline \multicolumn{5}{|l|}{ Day 9} \\
\hline Number of sucklings/d & $36 \cdot 8$ & $38 \cdot 3$ & 1.47 & 0.48 \\
\hline Average duration of one suckling (min) & $4 \cdot 19$ & $5 \cdot 01$ & 0.30 & 0.07 \\
\hline Total suckling time/d $(\mathrm{h})$ & $2 \cdot 56^{\mathrm{a}}$ & $3 \cdot 17^{\mathrm{b}}$ & 0.18 & 0.03 \\
\hline \multicolumn{5}{|l|}{ Body weight $(\mathrm{kg})(n 8)$} \\
\hline Day 1 (birth) & 1.40 & $1 \cdot 48$ & 0.07 & 0.44 \\
\hline Day 7 & $2 \cdot 69^{a}$ & $3.00^{\mathrm{b}}$ & 0.09 & 0.03 \\
\hline Day 14 & $4 \cdot 71$ & $5 \cdot 12$ & $0 \cdot 18$ & 0.13 \\
\hline Day 21 & $7 \cdot 04$ & $7 \cdot 35$ & 0.16 & 0.20 \\
\hline Day 28 & $9 \cdot 14^{\mathrm{a}}$ & $9 \cdot 84^{b}$ & 0.21 & 0.03 \\
\hline Weight gain, day $1-28$ (g/d) & $274^{a}$ & $298^{\mathrm{b}}$ & 8 & 0.05 \\
\hline
\end{tabular}

${ }^{a, b}$ Mean values within a column with unlike superscript letters were significantly different $(P<0.05)$.

For details of diets and procedure, see pp. 335-336.

(feed intake 4.9 (SEM 0.3) kg/d; weight at weaning 208(SEM 7) $\mathrm{kg}$ ), control sows suckling piglets born to sows supplemented with L-carnitine (feed intake $4.8 \mathrm{~kg} / \mathrm{d}$, weight at weaning $207 \mathrm{~kg}$ ), sows supplemented with L-carnitine suckling piglets born to control sows (feed intake $5.1 \mathrm{~kg} / \mathrm{d}$, weight at weaning $207 \mathrm{~kg}$ ) and sows supplemented with L-carnitine suckling piglets born to sows supplemented with L-carnitine (feed intake $4.5 \mathrm{~kg} / \mathrm{d}$, weight at weaning $203 \mathrm{~kg}$ ).

Total litter size, number of piglets born alive and birth weights of the piglets and litters did not differ between control sows and sows supplemented with L-carnitine. Taking all pregnant sows in the experiment, values for control sows (n 13) and sows supplemented with L-carnitine ( $n$ 16) were: number of piglets born/litter, $10.9 v .10 \cdot 9$ (SEM 0.8); number of piglets born alive/litter, 10.8 v. 10.6 (SEM 0.8); litter weight, $14.7 v .13 .6$ (SEM 0.9) $\mathrm{kg}$; piglet weight, $1.38 v .1 .32$ (SEM 0.04$) \mathrm{kg}$. The variation in body weights of piglets in a litter was similar in the L-carnitine treated sows and the control sows (the SD of piglet weights in the litters of control sows and of L-carnitine-supplemented sows being 0.14 and $0.18 \mathrm{~kg}$, respectively).

Taking the ten sows of each group that were studied during lactation, there was again no difference in these parameters; for control sows $(n$ 10) $v$. sows supplemented with L-carnitine ( $n$ 10): number of piglets born/litter, $10 \cdot 3$ v. 10.9 (SEM 0.9); number of piglets born alive/litter, $10.2 v .10 .4$ (SEM 0.9); litter weight, 14.2 v. 13.9 (SEM 0.9) $\mathrm{kg}$; piglet weight, 1.41 v. $1.36(\mathrm{SEM} 0 \cdot 06) \mathrm{kg}$.

Experiment 2: Concentrations of free and total carnitine in the milk of the sows and plasma carnitine concentrations of piglets at birth and during the suckling period

The sows supplemented with L-carnitine had higher concentrations of total L-carnitine in their colostrum (203 v. 151
(SEM 15) $\mu \mathrm{mol} / \mathrm{l}, P<0.05 ; n 10$ for each group) and milk on day 7 (127 v. 98 (SEM 9) $\mu \mathrm{mol} / 1, P<0.05 ; n 10$ for each group). The concentration of free L-carnitine in the milk was relatively low and did not differ between the milk from control sows and that from L-carnitine-supplemented sows, the values in control sows $v$. sows supplemented with L-carnitine being: colostrum, $10 \cdot 1$ v. 10.5 (SEM 1.2) $\mu \mathrm{mol} / \mathrm{l}$; milk on day $7,44 \cdot 4$ v. $43 \cdot 1$ (SEM 5.4) $\mu \mathrm{mol} / 1$.

At birth, piglets born to sows supplemented with L-carnitine had higher concentrations of total carnitine in their plasma than did piglets born to control sows $(P<0 \cdot 05$, Table 3$)$. On day 14 , the plasma carnitine concentrations of piglets born to control sows and of piglets born to sows supplemented with L-carnitine were no longer different, but piglets suckled by sows supplemented with L-carnitine had higher plasma carnitine concentrations than those suckled by control sows $(P<0 \cdot 05$, Table 3$)$. On day 28, piglets born to sows supplemented with L-carnitine and suckled by sows supplemented with L-carnitine had the highest plasma carnitine concentrations, and piglets born to control sows and also suckled by control sows had the lowest. Nevertheless, ANOVA showed that the origin of the piglets and the treatment of the sow during lactation did not influence the plasma L-carnitine concentrations of piglets on day 28 (Table 3 ).

\section{Experiment 2: Suckling behaviour of the piglets and weight gains of the piglets during the suckling period}

The number of sucklings/d at $3 \mathrm{~d}$ of age was no different between litters born to control sows and litters born to sows supplemented with L-carnitine (Table 4). There was also no difference in the number of sucklings between litters suckled by control sows and litters suckled by L-carnitine-supplemented sows. The average duration of one suckling was, however, higher in litters born to sows supplemented 
Table 3. L-Carnitine concentrations in plasma of piglets born to control sows and piglets born to sows supplemented with L-carnitine, suckled either by control sows or by sows supplemented with L-carnitine, on days 1, 14 and 28 of age (experiment 2)

(Values are least-square means)

\begin{tabular}{|c|c|c|c|c|c|}
\hline \multirow[b]{2}{*}{ Litter born to } & \multirow[b]{2}{*}{ Litter suckled by } & \multirow[b]{2}{*}{$n$} & \multicolumn{3}{|c|}{ Total carnitine in plasma $(\mu \mathrm{mol} / \mathrm{l})$} \\
\hline & & & Piglets day 1 of age & Piglets day 14 of age & Piglets day 28 of age \\
\hline Control sow & Control sow & 5 & $12 \cdot 3^{b}$ & $12 \cdot 1^{\mathrm{b}}$ & $7 \cdot 7^{\mathrm{b}}$ \\
\hline Control sow & L-Carnitine-treated sow & 5 & $14 \cdot 2^{a, b}$ & $15 \cdot 1^{a, b}$ & $10 \cdot 3^{a, b}$ \\
\hline L-Carnitine-treated sow & Control sow & 5 & $18 \cdot 9^{\mathrm{a}, \mathrm{b}}$ & $10 \cdot 7^{\mathrm{b}}$ & $10 \cdot 4^{\mathrm{a}, \mathrm{b}}$ \\
\hline L-Carnitine-treated sow & L-Carnitine-treated sow & 5 & $23 \cdot 5^{\mathrm{a}}$ & $17 \cdot 2^{\mathrm{a}}$ & $12 \cdot 3^{a}$ \\
\hline SEM & & & $2 \cdot 9$ & $1 \cdot 2$ & 1.5 \\
\hline Control sow & & 10 & $13 \cdot 3^{b}$ & $13 \cdot 6$ & $9 \cdot 0$ \\
\hline L-Carnitine-treated sow & & 10 & $21 \cdot 2^{\mathrm{a}}$ & $13 \cdot 9$ & $11 \cdot 4$ \\
\hline SEM & & & $2 \cdot 1$ & $0 \cdot 8$ & $1 \cdot 1$ \\
\hline \multicolumn{6}{|l|}{ Litter suckled by } \\
\hline Control sow & & 10 & $15 \cdot 6$ & $11 \cdot 4^{\mathrm{b}}$ & $9 \cdot 1$ \\
\hline L-Carnitine-treated sow & & 10 & $18 \cdot 9$ & $16 \cdot 2^{\mathrm{a}}$ & $11 \cdot 3$ \\
\hline SEM & & & $2 \cdot 1$ & 0.8 & $1 \cdot 1$ \\
\hline \multicolumn{6}{|l|}{ Results of ANOVA, $P$} \\
\hline Interaction & & & 0.65 & 0.14 & 0.81 \\
\hline
\end{tabular}

a,b Mean values within a column with unlike superscript letters were significantly different $(P<0.05)$.

For details of diets and procedure, see pp. 335-336.

with L-carnitine than in litters born to control sows $(P<0.05$, Table 4). The total suckling time/d was also higher in litters from sows supplemented with L-carnitine than in litters from control sows $(P<0.05$, Table 4$)$. Litters suckled by control sows and litters suckled by sows supplemented with L-carnitine did not differ in the average duration of one suckling and the total suckling time/d.

At birth, piglets born to control sows and those born to sows supplemented with L-carnitine did not differ in their weights (1.40 v. 1.36 (SEM 0.05) kg). Body weight gains between birth and day 7, and body weight gains between days 7 and 14 , were greater in piglets born to sows supplemented with L-carnitine than in piglets born to control sows $(P<0.05)$, irrespective of whether they were suckled by control sows or by sows supplemented with L-carnitine (Table 5). Body weights on day 14 were also significantly greater in piglets born to sows supplemented with L-carnitine than in piglets born to control sows (4.67 v. 4.32 (SEM 0.12) kg, $P<0.05$ ). Body weight gains between days 14 and 21 , and between days 21 and 28 , did not differ between piglets born to control sows

Table 4. Suckling behaviour (number of sucklings/d, average duration of one suckling and total suckling time/d) of piglets born to control sows and piglets born to sows supplemented with L-carnitine, suckled either by control sows or by sows supplemented with L-carnitine, at day 3 of age (experiment 2)

(Values are least-square means)

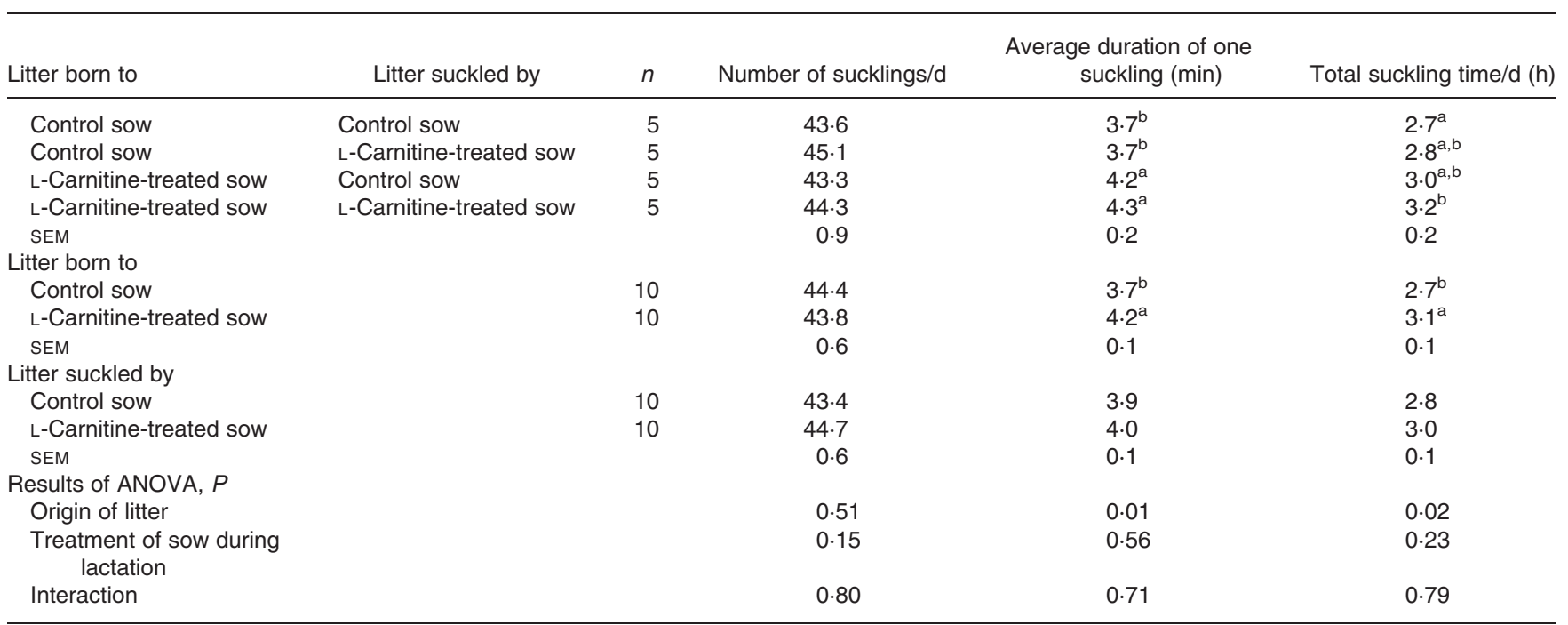

${ }^{\mathrm{a}, \mathrm{b}}$ Mean values within a column with unlike superscript letters were significantly different $(P<0.05)$.

For details of diets and procedure, see pp. 335-336. 
Table 5. Weight gains of piglets born to control sows and piglets born to sows supplemented with L-carnitine, suckled either by control sows or by sows supplemented with L-carnitine (experiment 2)

(Values are least-square means)

\begin{tabular}{|c|c|c|c|c|c|c|c|}
\hline \multirow[b]{2}{*}{ Litter born to } & \multirow[b]{2}{*}{ Litter suckled by } & \multirow[b]{2}{*}{$n$} & \multicolumn{5}{|c|}{ Body weight gain $(g / d)$} \\
\hline & & & Day 1-7 & Day $7-14$ & Day $14-21$ & Day 21-28 & Day $1-28$ \\
\hline Control sow & Control sow & 5 & $164^{\mathrm{b}}$ & $237^{\mathrm{b}}$ & 263 & 322 & 246 \\
\hline Control sow & L-Carnitine-treated sow & 5 & $175^{\mathrm{ab}}$ & $256^{a, b}$ & 290 & 320 & 260 \\
\hline L-Carnitine-treated sow & Control sow & 5 & $189^{\mathrm{ab}}$ & $292^{\mathrm{a}}$ & 254 & 327 & 266 \\
\hline L-Carnitine-treated sow & L-Carnitine-treated sow & 5 & $191^{\mathrm{a}}$ & $274^{a, b}$ & 292 & 329 & 271 \\
\hline SEM & & & 9 & 18 & 19 & 22 & 11 \\
\hline Control sow & & 10 & $170^{\mathrm{b}}$ & $246^{\mathrm{b}}$ & 277 & 321 & 253 \\
\hline L-Carnitine-treated sow & & 10 & $190^{a}$ & $283^{a}$ & 273 & 328 & 269 \\
\hline SEM & & & 6 & 13 & 13 & 16 & 8 \\
\hline \multicolumn{8}{|l|}{ Litter suckled by } \\
\hline Control sow & & 10 & 177 & 265 & 259 & 325 & 256 \\
\hline L-Carnitine-treated sow & & 10 & 183 & 265 & 291 & 325 & 266 \\
\hline SEM & & & 6 & 13 & 13 & 16 & 8 \\
\hline \multicolumn{8}{|l|}{ Results of ANOVA, $P$} \\
\hline Interaction & & & 0.22 & 0.31 & 0.79 & 0.93 & 0.71 \\
\hline
\end{tabular}

a,b Mean values within a column with unlike superscript letters were significantly different $(P<0.05)$.

For details of diets and procedure, see pp. 335-336.

and those born to sows supplemented with L-carnitine (Table 5 ). The weight gain during the entire suckling period (birth to day 28) did not differ between piglets born to control sows and those born to sows supplemented with L-carnitine (Table 5). Body weights on day 28 did not differ between piglets born to sows supplemented with L-carnitine and those born to control sows (8.88 v. 8.50 (SEM 0.23) kg, $P>0.05$ ). Litters suckled by sows supplemented with L-carnitine did not differ in their weight gains from those suckled by control sows during the entire suckling period (Table 5).

\section{Discussion}

In this study, sows were supplemented with L-carnitine during pregnancy and lactation. In both experiments, L-carnitine supplementation of the sows did not increase the weights of the litters or of individual piglets at birth. This is in disagreement with recent studies that have demonstrated, in large groups of sows, that L-carnitine supplementation significantly increased the weights of litters and of individual piglets (Musser et al. 1999b; Eder et al. 2001; Ramanau et al. 2002). We are aware that, because of the small number of sows used, the experiments presented here are not suitable to study the effects of L-carnitine on litter parameters at birth. Interestingly, in both experiments, more sows conceived in the L-carnitine group than in the control group. This finding agrees with results of a recent study that also looked at a small number of sows (Birkenfeld et al. 2006), suggesting that L-carnitine supplementation could improve the pregnancy rate of sows. However, no study with a larger number of sows has been performed that shows a beneficial effect of L-carnitine supplementation on pregnancy rate.

In the first experiment of the present study, piglets from sows supplemented with L-carnitine had greater body weight gains during the $28 \mathrm{~d}$ suckling period than did piglets from control sows. This finding agrees with our recent studies
(Eder et al. 2001; Ramanau et al. 2002, 2004, 2005). Moreover, the first experiment demonstrates that the piglets of sows supplemented with L-carnitine are able to suckle for a longer time/d at 3, 6, and 9 days of age compared with the piglets of control sows.

The second experiment was designed to find out whether the beneficial effects of L-carnitine supplementation of sows on the suckling behaviour and growth of the piglets during the suckling period were induced during the piglets' prenatal or postnatal phase. We observed that piglets born to sows supplemented with L-carnitine were able to suckle for longer on day 3 and grew faster during the first $14 \mathrm{~d}$ of the suckling period than did piglets born to control sows, irrespective of whether they were suckled by control sows or by sows supplemented with L-carnitine. This observation demonstrates that the effects of L-carnitine supplementation during pregnancy were responsible for the higher postnatal growth of the piglets, and that L-carnitine supplementation of lactating sows did not influence the growth of the suckling piglets.

It has been shown that sows exposed to increased suckling demand, e.g. by nursing heavier piglets or nursing piglets more frequently, produce more milk (King et al. 1997; Auldist et al. 2000). More prolonged suckling by the piglets may have imposed a greater suckling demand on the sow, which may in turn have stimulated the sow's milk production. We recently observed that the piglets of sows supplemented with L-carnitine are able to obtain more milk from the sow than are the piglets of control sows (Ramanau et al. 2004, 2005). The present study shows that this effect is due to increased suckling activity by piglets born to sows supplemented with L-carnitine. The higher milk intake of the piglets as a result of increased suckling activity explains their higher growth rate during the suckling period.

We were unable, for technical reasons, to study the suckling behaviour of the piglets after day 9. As the piglets of sows supplemented with L-carnitine tended to have higher growth 
rates than the piglets of control sows, even in the last week of the suckling period, we assume that the piglets in those litters had a more favourable suckling behaviour and a higher milk intake than the piglets of control sows after day 9 as well. It has been shown that energy and nutrient contents, as well as the fatty acid composition of the milk, do not differ between sows supplemented with L-carnitine and control sows (Ramanau et al. 2004, 2005). Milk composition might therefore not play a role with regard to differences in growth rate between piglets from control sows and from sows supplemented with L-carnitine. We cannot rule out the idea that the piglets of sows supplemented with L-carnitine might be suckled not only for a longer time each day but also with more vigour than the piglets of control sows. This hypothesis could not, however be tested in this study.

The finding that piglets suckled by control sows did not differ in body weight gain from piglets suckled by sows supplemented with L-carnitine demonstrates that L-carnitine supplementation did not influence the milk yield of the sow. It has been shown that the size and the milk yield of the mammary gland increases with an increasing number of fetuses. This has been linked to a greater placental lactogen level (Forsyth, 1986; Forsyth \& Wallis, 2002). In a recent study, sows supplemented with L-carnitine had a significantly higher number of newborn piglets than control sows (Ramanau et al. 2004). The increased number of piglets could have led to increased placental lactogen levels, which could in turn have led to increased mammary gland sizes; this may have contributed to the increased milk yield observed in the sows supplemented with L-carnitine in that study. In the present study, L-carnitine supplementation did not influence the number of piglets in both experiments and probably did not influence the release of placental lactogen and the development of the mammary gland. This matches with the finding that L-carnitine supplementation did not influence the milk yield of the sows.

The present study shows that L-carnitine supplementation during lactation does not influence the suckling behaviour of the piglets and their growth during the suckling period. This observation agrees with results of Musser et al. (1999a,b), who studied the effects of L-carnitine supplementation during pregnancy and lactation separately. These authors showed that L-carnitine supplementation of the sows during pregnancy increased litter weight gains during the suckling period, whereas L-carnitine supplementation during lactation alone did not. There was some disagreement between the two experiments in that piglets born to sows supplemented with L-carnitine in the first experiment showed higher body weight gains during the entire $28 \mathrm{~d}$ suckling period, whereas in the second experiment they had higher body weight gains compared with the piglets of control sows only during the first $14 \mathrm{~d}$. There could be several reasons for this discrepancy as the experimental conditions were not identical in the two experiments. Nevertheless, data from both experiments show that the L-carnitine supplementation of sows during gestation increases the weight gains of their litters during the suckling period, regardless of whether or not the sows received L-carnitine during lactation.

The reason for the increased suckling activity observed in piglets born to sows supplemented with L-carnitine is unclear. As the piglets of sows supplemented with L-carnitine did not differ from those of control sows in their initial body weights, and as litters were standardised to an identical number of piglets, the possibility that differences in litter sizes or piglet weights could play a role in influencing suckling behaviour and postnatal growth rates can be ruled out. It could be that the improved L-carnitine status at birth, as assessed by higher plasma L-carnitine concentrations, increased the suckling activity of the piglets from sows supplemented with L-carnitine.

Immediately after birth, L-carnitine plays an important role in energy production. During the intrauterine phase, the fetal supply of amino acids, glucose, minerals and fatty acids from the mother via the placenta is essential for fetal development. The rate of fatty acid oxidation in the fetus is low (Novak et al. 1981). Immediately after birth, however, the oxidation of fatty acids becomes important because of the discontinuation of the glucose supply and the rapid exhaustion of glycogen stores (Warshaw \& Curry, 1980). Sufficient concentrations of L-carnitine in the tissues are required for the utilisation of fatty acids for energy production. L-Carnitine is required for both the release of fatty acids from adipose tissue and fatty acid utilisation (Hahn, 1982; Novak et al. $1975 a, b)$. We suspect that the piglets of sows supplemented with L-carnitine were able to switch on fatty acid oxidation faster than the piglets of control sows. Greater fatty acid oxidation leads to increased energy and heat production on the part of the piglets, which might in turn have increased their suckling persistence during the first few days after birth.

However, L-carnitine status alone cannot explain the differences in suckling behaviour and body weight gain between piglets born to sows supplemented with L-carnitine and those born to control sows. If L-carnitine status alone had been responsible for suckling behaviour and growth during the suckling period, piglets suckled by sows treated with L-carnitine would have grown faster than piglets suckled by control sows, at least after the second week, because they had higher plasma L-carnitine concentrations on day 14 than piglets suckled by control sows. Yet the weight gains of the litters did not differ between piglets suckled by sows supplemented with L-carnitine and those suckled by control sows.

Musser et al. (1999b) suggested that the L-carnitine supplementation of sows increases the intrauterine nutrition and development of the fetuses. These authors also showed that piglets born to sows supplemented with L-carnitine had more muscle fibres, a greater loin depth, a higher percentage of lean and less backfat than the piglets of control sows, which might be due to higher maternal plasma concentrations of insulin-like growth factor-1 (Musser et al. 2000, 2001). It is conceivable that improved fetal development as a result of maternal supplementation with L-carnitine could have led to increased piglet vitality at birth, which might have been associated with increased persistence of suckling. This suggestion remains speculative, however, because we did not measure parameters of piglet vitality.

It is known that the endogenous synthesis of carnitine is extremely low in the fetus and during the first week of life, increasing thereafter (Borum, 1981; Baltzell et al. 1987; Coffey et al. 1991). Higher plasma L-carnitine concentrations at birth observed in piglets born to sows supplemented with L-carnitine might be due to an increased transplacental supply of L-carnitine to the fetuses. It has previously been shown that supplementing sows with L-carnitine increases 
their plasma L-carnitine concentration (Musser et al. 1999b; Ramanau et al. 2004, 2005). As L-carnitine can cross the placenta, increased maternal plasma L-carnitine concentrations may lead to higher fetal plasma carnitine concentrations (Lahjouji et al. 2004; Grube et al. 2005). Higher plasma carnitine concentrations on day 14 in piglets suckled by sows supplemented with L-carnitine compared with piglets suckled by control sows might be due to a higher L-carnitine intake with the milk. The finding that the milk of sows supplemented with L-carnitine contains more L-carnitine than the milk of control sows agrees with the results of recent studies (Ramanau et al. 2004, 2005). Interestingly, plasma L-carnitine concentrations on day 28 were no longer different between piglets suckled by sows supplemented with L-carnitine and piglets suckled by control sows.

In conclusion, this study shows that piglets born to sows supplemented with L-carnitine are able to suckle for longer in the early suckling period, obtain more milk and grow faster during the first $14 \mathrm{~d}$ of life than piglets born to control sows. It has also been shown that this effect is due to supplementation of the sows with L-carnitine during gestation. The practical implication of this study is that L-carnitine must be administered to sows during gestation to obtain beneficial effects on the growth of their litters during the suckling period.

\section{References}

Auldist DE, Carlson D, Morrish L, Wakeford CM \& King RH (2000) The influence of suckling interval on milk production of sows. J Anim Sci 78, 2026-2031.

Auldist DE, Morrish L, Eason P \& King RH (1998) The influence of litter size on milk production of sows. Anim Sci 67, 333-337.

Baltzell JK, Bazer FW, Miguel SG \& Borum PR (1987) The neonatal piglet as a model for human neonatal carnitine metabolism. $J$ Nutr 117, 754-757.

Bassler R \& Buchholz H (1993) Methodenbuch Band III. Die chemische Untersuchung von Futtermitteln, 3. Ergänzungslieferung. Darmstadt: VDLUFA-Verlag.

Birkenfeld C, Doberenz J, Kluge H, Eder K (2006) Effect of L-carnitine supplementation of sows on L-carnitine status, body composition and concentrations of lipids in liver and plasma of their piglets at birth and during the suckling period. Anim Feed Sci Technol (Epublication ahead of print version)

Borum PR (1981) Possible carnitine requirement of the newborn and the effect of genetic disease on the carnitine requirement. Nutr Rev 39, 385-390.

Coffey TM, Shireman RB, Herman DL \& Jons EE (1991) Carnitine status and lipid utilization in neonatal piglets fed diets low in carnitine. J Nutr 121, 1047-1053.

Eder K, Ramanau A \& Kluge H (2001) Effect of L-carnitine supplementation on performance parameters in gilts and sows. J Anim Physiol Anim Nutr 85, 73-80.

Forsyth IA (1986) Variation among species in the endocrine control of mammary growth and function: the roles of prolactin, growth hormone, and placental lactogen. J Dairy Sci 69, 886-903.

Forsyth IA \& Wallis M (2002) Growth hormone and prolactin-molecular and functional evolution. J Mamm Gland Biol Neopl 7, 291-312.

Gesellschaft für Ernährungsphysiologie (Ausschuß für Bedarfsnormen) (1987) Energie- und Nährstoffbedarf landwirtschaftlicher Nutztiere, Nr. 4 Schweine, pp. 30-43. Frankfurt/Main: DLG-Verlag.
Grube M, Schwabedissen HM, Draber K, Prager D, Moritz KU, Linnemann K, Fusch C, Jedlitschky G \& Kroemer HK (2005) Expression, localization, and function of the carnitine transporter octn2 (slc22a5) in human placenta. Drug Metabol Dispos 33, 31-37.

Hahn P (1982) Development of lipid metabolism. Апnи Rev Nutr 2, 91-111.

King RH, Mullan BP, Dunshea FR \& Dove H (1997) The influence of piglet body weight on milk production of sows. Livest Prod Sci 47, 169-174.

Lahjouji K, Elimrani I, Lafond J, Leduc L, Qureshi IA \& Mitchell GA (2004) L-carnitine transport in human placental brush-border membranes is mediated by the sodium-dependent organic cation transporter OCTN2. Am J Physiol Cell Physiol 287, C263-C269.

McGarry JD \& Foster DW (1976) An improved and simplified radioisotopic assay for the determination of free and esterified carnitine. J Lip Res 17, 277-281.

Musser RE, Dritz SS, Goodband RD, Tokach MD, Davis MD, Nelssen JL, Owen KQ, Hanni S, Bauman JS \& Heintz M (2000) Added L-carnitine in sow gestation diet improves carcass characteristics of the offspring. J Anim Sci 78, Suppl. 2, 30.

Musser RE, Goodband RD, Owen KQ, Davis MD, Tokach MD, Dritz SS \& Nelssen JL (2001) Determining the effect of increasing L-carnitine additions on sow performance and muscle fiber development of the offspring. J Anim Sci 79, Suppl. 2, 65.

Musser RE, Goodband RD, Tokach MD, Owen KQ, Nelssen JL, Blum SA, Campbell RG, Smits R, Dritz SS \& Civis CA (1999a) Effects of L-carnitine fed during lactation on sow and litter performance. J Anim Sci 77, 3296-3303.

Musser RE, Goodband RD, Tokach MD, Owen KQ, Nelssen JL, Blum SA, Dritz SS \& Civis CA (1999b) Effects of L-carnitine fed during gestation and lactation on sow and litter performance. J Anim Sci 77, 3289-3295.

Novak M, Monkus EF, Chung D \& Buch M (1981) Carnitine in the perinatal metabolism of lipids. I. Relationship between maternal and fetal plasma levels of carnitine and acylcarnitines. Pediatrica 67, 95-100.

Novak M, Penn-Walker D, Hahn P \& Monkus EF (1975a) Effect of carnitine on lipolysis in subcutaneous adipose tissue of newborns. Biol Neonate 25, 84-94.

Novak M, Penn-Walker D \& Monkus EF (1975b) Oxidation of fatty acids by mitochondria obtained from newborn subcutaneous (white) adipose tissue. Biol Neonate 25, 95-107.

Pluske JR \& Dong GZ (1998) Factors influencing the utilization of colostrums and milk. In The Lactating Sow, pp. 45-70 [MWA Verstegen, PJ Moughan and JW Schrama, editors]. Wageningen, The Netherlands: Wageningen Pers.

Ramanau A, Kluge H \& Eder K (2005) Effects of L-carnitine supplementation on milk production, litter gains and backfat thickness in sows with a low energy and protein intake during lactation. $\mathrm{Br} \mathrm{J}$ Nutr 93, 717-721.

Ramanau A, Kluge H, Spilke J \& Eder K (2002) Reproductive performance of sows supplemented with dietary L-carnitine over three reproductive cycles. Arch Anim Nutr 56, 287-296.

Ramanau A, Kluge H, Spilke J \& Eder K (2004) Supplementation of sows with L-carnitine during pregnancy and lactation improves growth of the piglets during the suckling period through increased milk production. $J$ Nutr 134, 86-92.

Spinka M, Illmann G, Algers B \& Stetkova Z (1997) The role of nursing frequency in milk production in domestic pigs. J Anim Sci 75, $1223-1228$.

Warshaw JB \& Curry E (1980) Comparison of serum carnitine and ketone body concentrations in breast- and in formula-fed newborn infants. J Pediatr 97, 122-125. 